\title{
Policy Deficit in Distance Education: A Transactional Distance
}

\author{
Sushita Gokool-Ramdoo \\ University of South Australia
}

\begin{abstract}
This paper innovatively extends the application of transactional distance theory (TDT) to evidence-based policy development in Mauritius. In-depth interview data on student persistence from a range of stakeholders is used to understand the implications of distance education (DE) policy deficit. Policy deficit has surfaced as another dimension of transactional distance and student persistence as an appropriate measuring instrument. Transactional distance is salient in the non-alignment of national and institutional DE planning. Associated results are myopic institutional vision, stagnating national plans, poor resource deployment, and ill-understood opportunities for personal development. This research validates TDT as an instrument for policy development and concludes that supporting advocacy plans will help to achieve sustainable distance education in the region. Lessons from the field in Mauritius can be usefully adapted to the sub-Saharan African context (SSA). These preliminary indications require further research and discussion.
\end{abstract}

\section{Distance Education Policy Deficit}

This article argues that policy deficit in distance education (DE) results in a space for potential misunderstanding and ill-perceptions (Moore \& Kearsley, 1996, p. 200). At a national level, this may represent a lack of dynamism in the increasingly technology-driven educational sector and carry a centripetal rather than centrifugal motion in terms of development. Development is hereby understood as an unfolding of opportunities related to human and environmental potential that generally improves meaningfulness and quality of life. At an individual level, this may imply difficulties to access ranges of choice and opportunities. In DE terms, a policy deficit constitutes a transactional distance (Moore, 1993) and appropriate procedures must be devised in order to overcome this distance. The broad framework that acts as a matrix for the development and articulation of more specific ones is necessarily a national policy.

A national policy may be seen as a roadmap that establishes the vision of a government and its people. It draws on national resources, contributes to a better understanding of concepts that are related to national concerns, organizes more effective and efficient practice, and plans for positive 
changes (e.g., improving rather than increasing access, decreasing costs, attracting investors, enhancing public confidence at local and international levels, and so forth). "Policy typically speaks to context, resources, activities, and desired outcomes" (Pacey \& Keough, 2003, p. 402). Policy helps to identify the appropriateness of the types of provision in specific contexts/cultures (Beaudoin, 2007). Development areas include program development, staff training, advocacy for stakeholders (including policy makers), market research, decisions about the appropriateness of available distance education, provisos for accompanying ICT legal frameworks, and funding lobbied for and provided in national budgets, among others. To guide its effective growth there is increased emphasis on the need for DE policies (Simonson \& Bauck, 2003), and the lack thereof implies barriers to people's participation in personal and national development activities. For optimal effectiveness of its operationalization, a national policy should reflect a nation's vision, should be the matrix within which institutional policy is developed, and should be implementable and demonstrably progressive (Honig, 2006).

Documentary evidence indicates that with the exception of a Lushophone country, Mozambique (SARDEC, 2005), there is no dedicated national DE policy in Anglophone and Francophone subSaharan Africa (SSA) in general. A range of DE institutional policy development based on general educational policy documents reveals DE provision and processes that are ill-delineated, despite the proliferation of DE activity in many of the countries (for instance, Botswana, South Africa, Namibia, and Mauritius, to name a few). Generally this research allowed the following points with regards to situations of national policy deficit to surface: (1) Despite the proliferation of institutional DE activities, institutional directions can conflict with national objectives; (2) Institutional development is limited without dedicated resources; (3) With transactional distance taken as a space for potential misunderstanding (Moore \& Kearsley, 1996), policy deficit contributes to ill-perceived and ill-understood national, personal, and institutional development requirements; and (4) Student persistence is suggested as an appropriate mechanism to gather intelligence for policy development because it connects supply-side and demand-side variables.

Data was obtained from the University of Mauritius DE participants through one-to-one interviews with students and with stakeholders (other than students). The limited numbers that were interviewed (students, $N=20$ and stakeholders, $N=10$ ), based on a convenience sampling approach, yielded results that are only indicative and not generalizable. However, the research process gave enough information for the construction of a policy development template that, with its potential for contextual/cultural sensitivities, could be applied to most SSA countries.

\section{Policy Deficit: A Dimension of Transactional Distance}

Based on the assumption that DE is a layered notion (Sauvé, 1993; Moore \& Kearsley, 1996, 2005), policy deficit is hereby taken as an additional layer of transactional distance when there is no agreed-upon charter on DE development, resulting in a limited range of available opportunities. Kinyanjui (1998) argues that aligned with national development plans, DE policies should promote, encourage, and support the orderly development of DE as well as associated technologies, infrastructure, and capacity building. Additionally, policies should help to enhance the effectiveness and management of DE at minimal economic and social costs. Pacey and 
Keough (2003) go on to suggest that the following areas should be considered when developing DE policy: academic, fiscal, geographic, governance, faculty, legal, student, technical, technological, and finally philosophical. Non-consideration of any one of these will usher in transactional distance.

Highlighting the importance of the specific context and national development parameters, Kaufman and Watkins (2003, p. 507) argue that institutional goals should be based on an understanding of the potential student market, and they should be aligned with the goals of the given society in which the institution operates. In addition, Lezburg (2003) and Sherry (2003) draw attention to the importance of accreditation and quality assurance issues that should inform a DE policy framework. This is even more significant if qualifications are required to be portable across nations. The appropriate mechanisms to distill such understanding into evidence-based, implementable, and demonstrable policy development (Honig, 2006, p.1) have to be devised and consensually agreed to.

Unfortunately, the absence or scant presence of such mechanisms in policy documents compounds the difficulty of accessing field information (Leary \& Berge, 2006) and eventual evidence-based interventions. DE policy deficit is more noticeable in SSA where many policy documents (e.g., White Papers 3 and 4 of South Africa and Education Master Plan for Mauritius) promote its access-oriented importance but do not delineate how to implement and achieve progress through DE. This is now discussed.

\section{DE Policy Deficit in Sub-Saharan Africa}

SSA includes a mix of Anglophone, Francophone and Lushophone countries, which are actively engaged in DE provision (ADEA/WGDEOL, 2003a; Gokool-Ramdoo, 2006; Wallet et al., 2007). Leary and Berge argue that Africa's heterogeneity leads to fragmented and uncoordinated DE provision (2007, p.136). Indeed policy and other documents surveyed indicate a complete absence of implementation processes, leaving this to institutional discretion. With institutional interests involved (whereby attracting public funding depends on the index of enrolment (Tresman, 2002; Inan et al., 2006), national interests of quality education may be compromised. A broad survey of the literature (ADEA/WGDEOL, 2003a \&b; Wallet \& Guidon, 2007; AmbeUva, 2007; Siaciwena \& Lubinda, 2008; Gulati, 2008) indicates that despite the avowed interest of many countries of the SSA in DE and a proliferation of institutional activities and institutional policy, countries like Botswana (Youngman, 2002; BFTU, 2007; Nhundu \& Kamau, undated; Braimo \& Lekoko, 2005; Bopelo, 2006; Sardec, 2005) and South Africa (ADEA/WGDEOL, 2003a; 2004; SAIDE, 2004; Badat, 2005; McKay, 2008) have no dedicated national policy that ensures representation of all interests. Policy-based transactional distance is however a relative concept.

Gulati highlights how ill-informed or non-existent DE policy in developing countries, including SSA, contributed to a number of problems, such as a diversion of resources from educational and technological infrastructures and teacher training as well as negative attitudes toward distance learning and social and cultural restrictions imposed on girls and women (Gulati, 2008, p.12). 
Policy deficits appear to have a snowball effect, one deficit compounding the implications of the other. For instance, if it is agreed that adult education would best be carried out through DE methodologies, a policy deficit situation in either or both will compromise the implementation of this agreement. Ambe-Uva (2007) demonstrates how the combined absence of an HIV/AIDS policy and a national DE policy in Nigeria disabled the Nigeria Open University from institutionalizing AIDS policy. Acting as a transactional distance, this compromised educational interventions that were potentially life-saving. Likewise, Zambia's educational policy paper (Siaciwena \& Lubinda, 2008), the different policy documents of Botswana (ADEA, 2003a) and South Africa (SAIDE, 2003), and the Draft Educational Strategic Plan of Mauritius (MEHR, 2008) highlight DE's potential to widen access, but its full-fledged implementation is conspicuously absent despite the fact that its multiplying use and institutional policy development are regularly noted. This deprives many audiences of educational opportunities. The focus is shifted now to Mauritius, an upper middle income SSA country (World Bank, 2009).

\section{DE Policy Development in Mauritius}

Policy-based transactional distance is also experienced in Mauritius. Official records indicate that first-generation DE was present as far back as 1865 in Mauritius with students registered on the London University external correspondence programs and examined locally (TEC, 2001). In 1971, the creation of the Mauritius College of the Air (MCA) to provide dedicated DE facilities, three years after independence, heralded a new era for DE. Indeed, Lord Young of Dartington was simultaneously setting up the UK Open University (UKOU) and the MCA in Mauritius. With the same vision informing both institutions, it would appear that the MCA carried as great a potential, albeit on a smaller scale, as the UKOU. However the UKOU became an internationally known institution informed by supporting policies, while a policy deficit led to the MCA's DE ambition being superseded by a more appealing media vocation. In the 1980s, there was renewed interest in second generation DE. Successively, consultants of international repute like Radcliffe (1988), Daniel (1989), and Lord Young again (1989) studied how to optimally develop and implement DE. Their reports were incorporated in the 1991 Master Plan on Education (MEAC, 1991), which highlighted the immediate need for coordination, planning, quality assurance, and prioritization as well as continuous evaluation of DE provision for working people, housewives, school drop-outs, or those wishing to continue learning.

The driving forces behind this initiative aimed at improved quality and cost-effectiveness of educational provision (MEAC, 1991, p.101). This became the dedicated role of the newly established Tertiary Education Commission (TEC) (MEAC, 1991, pp. 102-103) with regards to institutions under its purview. Again policy deficit led to ill-synchronized DE provision distributed among the MCA, the Mauritius Institute of Education, and the University of Mauritius. The initial implementation of the recommendations of the reports was not sustained and the major systemic restructuring that was required was not undertaken for "lack of national capacities of appropriation" (Sacks et al., 1996, p.14). Interestingly the policy deficit situation appears to be destined to persist because the recent Draft Education and Human Resources Strategy Plan 2008-2020 (MEHR, 2008) does not propose procedures to decrease transactional distances. Despite the long history and the reports that were instrumental in charting the first 
policy position, little has happened. The discourse remains prevalent but there is no demonstrable progress. The following analytical framework proved useful in understanding implications of national policy deficit at institutional and national levels.

\section{Theoretical Framework}

Two operational definitions have been retained for the purposes of this research project. Classical DE refers to those distance learning environments that favor print-based media, which may include audio-visual, satellite, telephony, and e-mail based transactions (Glikman, 2006, p.10) but preclude an electronic educational platform. Online DE refers to a type of educational transaction carried out on an electronic platform that favors student-student, student-content, and student-tutor interactions and carries all resources that support the learner's educational itinerary. The research framework and analytical matrix incorporated the following: transactional distance theory (TDT) (Moore, 1993; Moore \& Kearsley, 1996, 2007; Moore, 2007); Deschênes and Maltais's (2006) categorizing principles of student persistence (cognitive, metacognitive, and affective); a participative and inclusive outlook based on the systems approach (Saba, 2003, 2007); and the ADDIE-E model of program planning (Gokool-Ramdoo, 2008).

\section{Transactional Distance Theory (TDT)}

Since DE is characterized primarily by distance (Moore \& Kearsley, 1996) the most appropriate theory from which to study a DE problem is a DE theory. Gibson (2003) and Glickman (2006) flag the atheoretical nature of most research carried out by DE practitioners and the risks this represents in terms of understanding the discipline. TDT is concerned with independent study and highlights the shared responsibility of the teaching/learning enterprise with learner independence as the most important and desired outcome (Moore, 1993; Deschênes \& Maltais, 2006). This outcome is the result of shared negotiation through dialog and structure between multiple permutations and combinations involving relationships between and among teacher, learner, course material, institution, culture, country, and so forth to decrease possibilities of misunderstanding. It accommodates all forms of DE and provides a conceptual tool that helps students and others to place any DE program in relation to any other (Moore \& Kearsley, 1996).

\section{Student Persistence}

Student persistence is an important component in DE because without the learner there is no teaching/learning transaction (Sauvé, 1993). It is identified as a useful mechanism to gather market intelligence since it connects both the demand-side and supply-side perspectives. It implicitly carries consumer (student) and producer (institutional and state) perspectives. It is a function of teaching and learning activities and penetrates the core of institutional practice. 


\section{Deschênes and Maltais’'Organizing Principles of Student Persistence}

In discussing factors affecting student persistence, Deschênes and Maltais (2006) intertwined existing notions into principles for categorization. These became all-encompassing, organizing principles. Four essential aspects of the learning experience are covered by these principles: cognitive, the processing of information through instructional strategies to increase or broaden knowledge; affective, strategies that enhance the meaningfulness of the learning experience (based on extrinsic and intrinsic motivators, especially dealing with the realm of feelings); metacognitive, the awareness of and ability to manage one's own cognitive processes (Hannafin et al., 2007, p. 130), thus implying strategies that help the student organize and take responsibility for the learning experience; and socio-economic, which includes all the variables inherent in the student's public and private spaces that he/she interacts with and that may affect his/her affective and metacognitive, rather than cognitive, skills.

\section{The Systems Approach to DE Planning}

The systems approach (Moore \& Kearsley, 1996, p. 5) sees DE issues, appropriately, in a simultaneously compartmentalized and comprehensive manner with components and subcomponents that are seamlessly woven into a whole. While the sub-systems or components are broken down into easily manageable functions, one does not lose sight of the interrelationships between the parts. The original ADDIE model stands for analyze, design/develop, deliver, implement/interact, and evaluate (Cafarella, 2002; Moore \& Kearsley, 1996). It was modified to include an additional component, the environment (including context and culture at institutional and national levels) where the educational transaction takes place (Gokool-Ramdoo, 2008). It is seen as a template into which information about student and organizational needs (teachers, program developers, logistics, administration, and support components) are fed so that they are constantly reorganized with a view to providing a better fit between needs and provision, thus decreasing transactional distance. The additional 'e' in the comprehensive planning process recognizes the diversity of audiences and students' contextually/culturally driven needs. Thus globalization, technology, and leadership issues - the inter-articulation of which is more easily understood through the ADDIE-E model - also influence policy development (Dirr, 2003; Beaudoin, 2003; Woudstra \& Adria, 2003).

\section{Methodology}

\section{Inquiry Tools}

The TDT was useful for developing the interview schedules for students and stakeholders. It enabled probing into all the components of distance education, as indicated by the ADDIE-E model. Data from participants were collected in the first instance from in-depth individual interviews that lasted almost an hour each. The structured interview format enabled clarification, restatement, and explanation within a given focus to elicit responses from participants (Merriam \& Simpson, 2000, p. 152). 


\section{Participants and Programs}

The participants were recruited on the basis of convenience sampling (Trochim, 2006). The University of Mauritius has two DE departments: the Centre for Professional Development and Lifelong Learning (CPDL) and the Virtual Centre for Innovative Learning Technologies (VCILT). The CPDL offers diploma and bachelor level courses through classical DE and face-toface methods (see http://www.uom.ac.mu/CPDL/index.htm), and the VCILT offers certificate to master's level programs essentially through online technologies (see http://www.uom.ac.mu/CPDL/index.htm). DE provision is based on a blended model, which involves multiple face-to-face meetings. Study respondents were drawn from the DE student population as well as a range of stakeholders. Twenty students $(N=20)$ were interviewed: 10 classical $(n=10)$ and 10 online $(n=10)$ (see Table 1$)$.

Table 1

Profile of Classical $(C)$ and Online $(O)$ DE Learners

Demography Profile/Data

$\begin{array}{lllllllllllllllllllll}\text { Student number } & 1 & 2 & 3 & 4 & 5 & 6 & 7 & 8 & 9 & 10 & 11 & 12 & 13 & 14 & 15 & 16 & 17 & 18 & 19 & 20\end{array}$

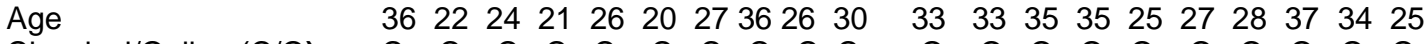

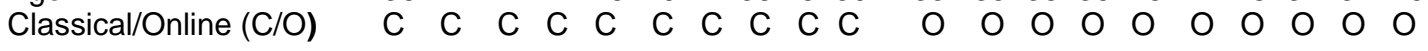

The online students were all postgraduates reading towards a master's of science degree in Computer Mediated Communication Pedagogies (CMCP). This program entailed an initial faceto-face induction with most tutorials being carried out on the online learning platform, Moodle. Occasional face-to-face sessions were organized on demand. The classical students were all undergraduates registered on two different programs, the bachelor's of science degree in Financial Management and the diploma in Management Studies respectively. The print-based, instructional-designed learning material relied heavily on weekly, Saturday face-to-face sessions. Stakeholders included students, teachers, instructional designers, administrators, and educational technologists. Table 2 indicates their position within the University as well as their relationship with students, type of DE experience, and duration of involvement in DE. 
Table 2

Profile of Respondents

\begin{tabular}{|c|c|c|c|c|c|c|c|c|c|c|}
\hline & 1 & 2 & 3 & 4 & 5 & 6 & 7 & 8 & 9 & 10 \\
\hline Gender & $\mathrm{F}$ & M & $\mathrm{M}$ & $\mathrm{F}$ & $\mathrm{M}$ & M & $\mathrm{F}$ & $\mathrm{M}$ & $\mathrm{F}$ & $\mathrm{F}$ \\
\hline Age & 35 & 38 & N/A & 36 & 38 & N/A & 34 & 30 & N/A & 44 \\
\hline Position & $\mathrm{I} / \mathrm{D}$ & AL/L & E. A & S.L & AL/L & $\mathrm{P}$ & AL/L & $\mathrm{S} / \mathrm{L}$ & AL/L & AP \\
\hline $\begin{array}{l}\text { Relation } \\
\text { with } \\
\text { students }\end{array}$ & $\mathrm{L}$ & L\&c/w & Admin & L\&c/w & L\&c/w & L\&c/w & L\&c/w & $\mathrm{L} \& \mathrm{c} / \mathrm{w}$ & L\&c/w & L\&c/w \\
\hline $\begin{array}{l}\mathrm{DE} \\
\text { experience } \\
\text { type }\end{array}$ & C & C & C & $\mathrm{C}$ & $\mathrm{C} \& \mathrm{O}$ & $\mathrm{O}$ & $\mathrm{O}$ & $\mathrm{O}$ & $\mathrm{O} \& \mathrm{C}$ & O\&C \\
\hline $\begin{array}{l}\text { Years of } \\
\text { experience }\end{array}$ & 11 & 2 & 13 & 6 & 5 & 20 & 5 & 7 & 5 & 7 \\
\hline
\end{tabular}

Key: Instructional Designer : I/D; Assistant Lecturer/Lecturer: AL /L ;Senior Lecturer:SL ; Associate Professor: AP ; Professor: P Lecturing/Course Writing: L/c/w; Executive Assistant: EA Online: O; Classical: C

Stakeholders $(N=10)$, i.e., administrators, course writers, managers, instructional designers, and teachers, were also interviewed; five $(n=5)$ belonged to each of the two distinct groups. Their voluntary participation was agreed to in their signed consent letters.

\section{Research Limitations: A Note of Caution}

Convenience sampling is a non-probability sampling method that relies on voluntary participation. As such it may leave out an important number of potential respondents. Responses are only indicative and not representative of the whole student population. In addition, convenience sampling does not allow the emergence of cross section data. Sampling size may impact negatively on generalizability and replicability. However available data provided sufficient pointers for the foundation of a policy on which other information may be grafted for use as the applications of the TDT are further extended.

\section{Findings}

Data indicated that policy deficit was indeed a transactional distance demonstrable through the gap between learner needs and institutional provision. No mechanism captured national requirements or learner needs, which called into question institutional provision as well as teaching/learning processes. Additionally, learner independence and persistence were not promoted as an engineered institutional strategy; rather, they were an accidental outcome. The qualitative findings were categorized according to the questions set, which fitted the organizing strands: cognitive, affective, and metacognitive strands respectively. These were further subcategorized into interaction and culture/context. Data generated by the stakeholders will be discussed, beginning with the students. 


\section{The Students}

During the interviews with the students the following notions pertaining to individual characteristics were kept in mind: age, earlier experiences, attitudes toward learning, resilience, autonomy (that is, whether or not they could easily study on their own or required assistance from teachers, peers, and/or the institution), awareness of support services as a concept and as a facility, profession, and level of program of study. Responses were divided into interaction and culture/context concerns.

\section{Interaction: Teacher/learner relationship.}

The teacher/learner relationship was the most discussed topic. Most classical students were simply concerned with completing the learning program; they took negative teacher responses in their stride. Some students expressed a sense of inadequacy with regards to encounters with authority, management, or teachers. Highly prevalent attitudes included fear of the teacher, anxiety regarding humiliating experiences, and unwillingness to take control of their learning. Student 1 helplessly recoiled at verbally violent situations that clearly were not conducive to positive interaction: "...A lecturer cannot shout at you, sorry."

In such cases, interaction could even foster counter cognitive impacts. Moreover, teachers' unavailability was perceived negatively. Student 2 reported the following: "The [teachers] don't have time to listen to you. My favorite teacher's class was very interactive; she invited a lot of participation. ... It's not the same for other teachers though."

While speaking about some teachers and their teaching styles, student 1 concurred: "Classes are monotonous and strongly lack interactivity: these are often only monologues... there is ...no way to raise interest in the subject, no real inspiration. There is a total lack of interactivity from the lecturer."

The 10 classical students appeared to have mixed feelings, ranging from boredom caused by the highly didactic face-to-face methods to inspiration spurred by committed teachers. The high number of students attending the time-constrained sessions led to limited opportunities for individualized interaction. This condition was borne as a hopefully short-lived sacrifice. Many teachers went the extra mile to meet learners individually, especially one inspirational teacher whose efforts were widely appreciated and who inspired the wish among students that such dedication could be replicated by other teachers. Online students were more positive and confident in their interactions with their teachers; this may be attributed to their professional and post-graduate status (most were teachers) and the accompanying level of self-confidence. However most $(n=18)$ expressed a strong need for the recreation of the teaching act similar to the classroom mode (Keegan, 1993), implying that learner autonomy was a rather alien concept among the students. 


\section{Interaction: Learner autonomy and support.}

Learner autonomy indicates the degree to which students are dependent on or independent of their environment in the pursuit of their studies. Metacognitive skills are necessary for the development of learner autonomy. Most classical distance learners required frequent teacher presence and support, thereby demonstrating lower levels of autonomy. Respondents concurred that the support that permitted the development of metacognitive skills was mostly available from their private spaces: family, spouses, or even bosses. Student 9 illustrated this generally held view as she anticipated changes in her life, e.g., marriage, and recognized the support provided by her fiancé and her in-laws. Also, she was able to persist because her boss "is doing his MBA and ... he is flexible since he is very understanding and keeps encouraging me in my [studies]."

Despite the lesser autonomy demonstrated by classical students, the mandatory weekly face-toface sessions were a controversial issue. Some students claimed that these were a necessary complement to the course material; others resented the sessions because they interfered with their personal commitments. They argued that the print-based material should have been comprehensive, and face-to-face sessions should not have been mandatory. Making the face-toface sessions elective would have spared students of the obligation of attending, especially when as adults they judged that they did not require particular sessions. This became a critical issue when attendance entailed major household reorganization efforts, including baby-sitting and so forth. They had difficulty reconciling their need for teachers' presence with their adult commitments and time constraints, which contributed to frustration and some views that sessions were of varying quality, relevance, and helpfulness. Student 5 expressed this frustration:

The course materials are not sufficient ... lecturers ... ask us to go to the library for further reference but this also becomes difficult because we have to work, ...we are free only on Saturdays and all our Saturdays are taken up with face to face sessions... [we] waste a lot of time depending on public transport. Time and transport become a problem...I have a lot of personal commitments... and often suffer from fatigue...

The students felt that the institution should have been more sensitive to their adult commitments and should have provided some solutions. Conversely, the online distance learners presented more field-independent characteristics, interacting when it was constructively or socially required. They claimed to be more in control and confident in negotiating their learning experience. They appeared to experience less transactional distance in terms of time, space, and interaction with their tutors, and they expressed their autonomy $(n=10)$. Teachers being just a click away and fellow students being accessible on Moodle or within easy geographic access enhanced that independence.

As with the classical learners, some insecurity gradually appeared in their need for the physical presence of the teacher or for institutional/technological support. Some indicated that the learning platform was problematic and that the choice of learning groups was not as democratic as they 
would have wished. This compromised the level of control they had over their leaning experience and impacted negatively on student-student-learning material interaction. It contributed to dysfunctional working groups as student 17 declared and as student 16 explained:

At times the platform would crash so ...that caused us a lot of problems for communication. Another problem was caused by the fact that we were not allowed to choose group members. The lecturers ... did that for us.

General interview data from the students $(N=20)$ revealed that their initial concern about interaction was gradually buried under the layers of time that passed as well as homework and personal and professional obligations. They accepted their choiceless lot without much complaint, and they were grateful for the opportunity to belong to a recognized university. What then was the element that prevented the institution from recording dissatisfaction with teaching/learning processes? The answer was culture.

\section{Culture and choiceless persistence.}

Cultural influences were highly pervasive. Students' docile and unquestioning demeanor characterized this. They trusted the fact that they were registered with a nationally recognized institution and had faith in the teaching/learning processes. While they found the concept of more independence desirable, nearly all students $(n=18)$ were worried about how to handle independence: teacher control was a habit that was difficult to undo. Accustomed to not contradicting teachers, students were mostly docile during interactions. They were reluctant to shift the locus of control from the teacher or organization, there were few complaints so as not to offend the teachers, and most students kept a very low profile, intent only on graduating. Their intrinsic desire for meaningful learning experiences was gradually superseded by the extrinsic motivation of simply earning a recognized qualification.

Students reported that DE programs were characterized by non-flexible and non-negotiable pacing. The purported lack of individual treatment was especially apparent in the cohort-based approach and the mandatory face-to-face sessions that encroached on students' private spaces. Many students, e.g., student 5, argued that this attitude held little regard for their personal circumstances. The students did not feel capable of discussing this issue despite the fact that they felt it strongly. Students were satisfied that the qualification given by the University of Mauritius was recognized and was a passport towards professional advancement, as shown by student 1's statement:

My final objective... is what is encouraging me to stay on this program. I am strongly motivated to complete this course, so ... nothing can urge me to drop out. Other reasons would be too minor. Whatever happens in the course or about the course does not really matter. 
While aware of the desirability of a meaningful learning experience, they were passive spectators of the way that education was delivered to them and were shortsighted about the opportunities that should have been available to them. Such information is crucial for evidence-based participatory policy development.

\section{The Stakeholders}

Stakeholder interview data revealed concerns that were similar to those expressed by the students. Responses were polarized in two directions: interaction and work culture. Among the 10 stakeholders interviewed, there were five who were engaged in classical distance education and five who were responsible for online DE provision. Among the classical DE staff, one was a fully trained instructional designer, who adroitly and effectively guided teams of subject experts. The online educational cadres were fully trained in educational technology $(n=3)$, while subject experts $(n=2)$ blended the electronic services with face-to-face provision. One classical distance teacher also taught campus-based students electronically. In addition, the teaching classical DE staff $(n=3)$ had a full working load with campus-based students. The interest in distance teaching of interviewed staff members stemmed from an intrinsic motivation to broaden their range of experiences. Responses again seemed to be polarized into interaction and culture, particularly work culture. Transactional distances seemed obvious.

\section{Interaction.}

In the absence of well-delineated DE institutional policy, stakeholders reported various challenges. Interaction was facilitated to some extent by the course material and the face-to-face sessions. However, some interviewees declared their dissatisfaction with the latter, prompted by their awareness of students' needs as well as their felt inadequacy to meet these needs through the course material. This inadequacy resulted directly from a policy deficit, which entailed their own unawareness of the implications and procedures for distance teaching and instructional design as well as the etiquette for interacting with students. This led to an uneven quality of the material, thus compromising interaction. Academic 1 pointed out the following: "Students are given manuals of uneven quality depending on the variable professional expertise of the teachers on the writing panel...There is ... no external review."

Although students had complained about the mandatory attendance at face-to-face meetings, this inordinate frequency of meetings was justified by teachers' felt insecurity and lack of confidence in DE as a quality teaching methodology. Again there was a need to re-create the classroom-type teaching act (Keegan, 1993), thus limiting opportunities for the development of metacognitive skills and learner autonomy. Under this pressure, stakeholders were worried that their workload may prevent them from providing adequate individualized interaction and feedback. Academic 2 reported that their most discussed needs must be addressed, such as training in DE methodologies, student support, and logistics and technical infrastructure that support interaction as well as the relevant work culture. 


\section{Work culture.}

Work culture involved institutional and national frames of reference. Participation in DE arose from curiosity or from a desire to earn some extra income or to gain new experience that could prove useful in future. The belief that the institutional direction was appropriate was dictated by the proud fact that the institutional policy had preceded a national one and the fact that the nationally recognized institution was responding to a few lines of the Master Plan (MEAC, 1991). However DE practice revealed some obstacles that could be ill-understood but doggedly overcome. The stakeholders reported being swamped under heavy workloads; they were generally ill-equipped to cope with the tensions involved with distance as well as face-to-face teaching. They expressed their desire for an appropriate policy to overcome this lacuna, including codified and communicated mechanisms and processes for recruitment, training, and staff retention (Sherry, 2003). The current policy deficit implied extra work with regards to DE practice, as academic 10 stated: "One needs to complete existing hours of work, so that's why not many lecturers are willing to undertake the extra load."

Flagging the national policy deficit concern, data indicated that academics felt the need for a dedicated policy that could help their professional planning. As academic 9 argued, "We need to have national guidelines for the country."

Despite the fact that the Master Plan (1991) had indicated the importance of developing DE and that no dissatisfaction was overtly documented regarding its deficient provision, its implementation was nowhere discussed. In conclusion, most stakeholders argued that the TEC had to be more forceful in its policy development and quality monitoring role in relation to the following issues: encouragement of further participation in DE initiatives, workload and recognition, individually and nationally responsive programs, marketing and student persistence, institutional leadership, quality, and policy framework.

\section{Conclusion}

The findings confirmed that policy could indeed be taken as another dimension of transactional distance. At an individual level, a national and institutional policy deficit meant that students were unaware of the implications of DE and of the opportunities for the flexibility of the program to work around their lives rather than the other way round. Students mainly persisted out of choicelessness and unawareness, which glossed over numerous glitches in the teaching/learning process. No mechanism existed to detect the students' personal circumstances, their level of preparedness to embark on distance education, the media format used, the type of program, the level of student maturity to handle the learning process, and their eventual satisfaction. Students did not have the spectrum of course choice and learning options that may be the most suitable for their needs. Metacognitive and affective skills remained undeveloped, especially learner autonomy.

An advocacy plan would help students to understand legitimate expectations from DE and to develop the necessary skills for interaction (tutor-student-course material-organization), for time- 
management (including skills to negotiate personal and professional commitment), and for the cultivation of necessary personality traits to seamlessly integrate local culture with innovative learning expectations. An important pillar of this plan is feedback mechanisms that would feed field intelligence from the students into policy development. This would continuously ensure the closeness of match between learners' cognitive, metacognitive, and affective circumstances and institutional provision. Awareness of the opportunities, benefits, and disadvantages of choosing this mode of learning over any other will equip the learner with the necessary confidence so that his or her progress is not a matter of choicelessness but of meaningfulness.

At an institutional level, policy will enhance existing commendable efforts, broaden professional opportunities, deploy resources effectively in such areas as capacity building, career planning, quality teaching, management, and administration, and support the development of reward and recognition programs. Capacity building will enhance quality by equipping cadres with the required skills to develop flexible and culturally responsive DE initiatives for the market and for nationally responsive interventions. Thus there is a need for national DE policy as a policy development matrix framed by the TDT, the systems approach, and the ADDIE-E model of program planning as well as by Deschênes \& Maltais' organizing principles for student persistence. Student persistence has been an appropriate mechanism that has usefully connected supply and demand side variables. This research has validated TDT as an instrument for policy development, which could be useful in Mauritius and in SSA. Evidence from the literature review and interview data has demonstrated the implications of a national policy deficit in SSA countries, including Mauritius. These preliminary indications need to be further researched and discussed. 


\section{References}

ADEA/WGEOL. (2002). Open and distance learning in sub-Saharan Africa - A literature survey on policy and practice. Paris: Komane, J., Mays, T., Naidoo, V., Dhanarajan, G., \& Glennie, J.

ADEA/WGDEOL. (2003a). Enseignement à distance et apprentissage libre en Afrique subsaharienne : Etat des lieux dans les pays francophones. Paris: Valérien, J., Guidon, J. ,Wallet, J., \& Brunswic, E.

Ambe-Uva, T. N. (2007). Combating HIV/AIDS epidemic in Nigeria: Responses from National Open University of Nigeria (NOUN). International Review of Research in Open and Distance Learning 8(3). http://www.irrodl.org/index.php/irrodl/article/view/458/981

Asunka, S. (2008). Online learning in higher education in sub-Saharan Africa: Ghanaian university students' and perceptions. International Review of Research in Open and Distance Learning. 9(3). http://www.irrodl.org/index.php/irrodl/article/view/9.3.1/1133

Badat, S. (2005). Distance higher education policies for access, social equity, quality, and social and economic responsiveness in a context of the diversity of provision. Council on Higher Education, South Africa. Distance Education, 26(2), 183-204.

Beaudoin, M.F. (2003). Distance education leadership: An appraisal of research and practice. In M.G. Moore \& W.G. Anderson (Eds.), Handbook of distance education (pp. 519-530). New Jersey: Lawrence Erlbaum Associates, Inc.

Beaudoin, M.F. (2007). Dissecting the African digital divide: Diffusing e-learning in sub-Saharan Africa. E-Learning, 4(4).

BFTU (2007). Policy on education in Botswana: The Botswana Federation of Trade Unions.

Bopelo, B. (2006). The draft Botswana ICT policy and its implications for quality distance education delivery. World Conference on Distance Education: ICDE22 Rio de Janeiro, Brazil. www.icde22.org.br/presentation/4/TC101Bopelo.ppt

Cafarella, R.S. (2002). Planning programs for adult learners. New York: Jossey- Bass.

Daniel, J. (1989). Distance education for human resources development in Mauritius: The way forward. A report to the Ministry of Education of the Government of Mauritius prepared at the request of the Commonwealth of Learning (COL). Vancouver, Canada: COL.

Deschênes, A. J., \& Maltais, M. (2006). Formation a distance et accessibilité. Sainte Foy, PQ: Tele- Université. 
Dirr, P.J. (2003). Distance education policy issues: Towards 2010. In M.G. Moore \& W.G. Anderson (Eds.), Handbook of distance education (pp. 461-480). New Jersey: Lawrence Erlbaum Associates, Inc.

Glikman, V. (2006). Preface. In A. J. Deschênes \& M. Maltais (Eds.), Formation a distance et accessibilite. Montréal, PQ.: Télé université.

Gokool-Ramdoo, S. (2008). Beyond the theoretical impasse: Extending the applications of transactional distance education theory. The International Review of Research in Open and Distance Learning, 9(3). http://www.irrodl.org/index.php/irrodl/article/view/541/1148

Gokool-Ramdoo, S. (2006). Open and distance learning in Anglophone countries of the subSaharan Africa: An update of the WGDEOL study, Open and distance learning in subSaharan Africa - A literature survey on policy and practice. Dakar:

BREDA/UNESCO/ADEA/WGTP/WGDEOL. http://www.edusud.org/adea/mauricec1.pdf

Gulati, S. (2008). Technology-enhanced learning in developing nations: A review. International Review of Research in Open and Distance Learning, 9(1). http://www.irrodl.org/index.php/irrodl/article/view/477/1011

Hannafin, M.J., Hill, J.R., Song, L., \& West, R.E. (2007). Cognitive perspectives on technology-enhanced distance learning environments. In M. G. Moore (Ed.) Handbook of distance education. (pp.43-57). Mahwah, NJ: Lawrence Erlbaum.

Inan, F.A, Yukselturk, E., \& Grant, M.M. (2006). Profiling potential dropout students by individual characteristics in an online certificate program. International Journal of Instructional Media, 36(2).

Keegan, D. (1993) (Ed.). Theoretical principles of distance education. UK: Routledge.

Kinyanjui, P.E. (1998). Distance education and open learning in Africa: What works or does not work. Paper presented at the EDI/World Bank Workshop on Teacher Education through Distance Learning. Addis Ababa, Ethiopia. Vancouver: Commonwealth of Learning. http://www.col.org.speeches/edi africa98.htm

Leary, J., \& Berge, Z. L. (2006). Trends and challenges of e-learning in national and international agricultural development. International Journal of Education and Development using ICT, 2(2). Retrieved June 26, 2009, from http://www.irrodl.org/index.php/irrodl/article/view/477/1012

Leary, J., \& Berge, Z. (2007). Successful distance education programs in sub-Saharan Africa. 
Turkish Online Journal of Distance Education, 8(12). Retrieved February 26, 2009, from http://tojde.anadolu.edu.tr/tojde26/pdf/article 12.pdf

Lee, Y., Driscoll, M. P., \& Nelson, D. W. (2004). The past, present, and future of research in distance education: Results of a content analysis. The American Journal of Distance Education, 18(4), 225-241.

MEAC. 1991. Education master plan for the year 2000. Mauritius: Ministry of Education, Arts and Culture.

MEHR, (2008). Draft education and human resources strategy plan 2008-2020. http://www.gov.mu/portal/goc/educationsite/file/DRAFT\%20EDUCATION\%20\&\%20H UMAN\%20RESOURCES\%20STRATEGY\%20PLAN\%20(2008-2020).doc

Merriam, S. B., \& Simpson, E. L. (2000) ( $2^{\text {nd }}$ ed.). A guide to research for educators and trainers of adults. Florida: Krieger Publishing Company.

Moore, M.G. (1993). Theory of transactional distance. In D. Keegan (Ed.), Theoretical principles of distance education. London: Routledge.

Moore, M., \& Kearsley, G. (1996). Distance education - A systems view. Belmont, CA: Wadsworth.

Moore, M. G. (2007). Theory of transactional distance. In M. G. Moore (Ed.), Handbook of distance education (pp. 89-101). Mahwah, NJ: Lawrence Erlbaum.

Nhundu, T.J., \& Kamau, J. W. (undated). From correspondence to open and distance learning: The Botswana experience. Centre for Continuing Education, University of Botswana.

Pacey, L., \& Keough, E. (2003). Public policy, institutional structures, and strategic implementation. In M.G. Moore \& W.G. Anderson (Eds.), Handbook of distance education (pp. 401-416). New Jersey: Lawrence Erlbaum Associates, Inc.

Radcliffe, J. (1988). The potential contribution of distance learning and audio-visual resources to educational development in Mauritius. A report to the Ministry of Education, Arts and Culture. UK: Milton Keynes.

Saba, F. (2003). Distance education theory, methodology, and epistemology: A pragmatic paradigm. In M. G. Moore \& W. G. Anderson (Eds.), Handbook of distance education (pp. 3-21). Mahwah, NJ: Lawrence Erlbaum.

Sacks, R., Tietjen, K., Hartwell, A, \& Shaw, C. (1996). Formulating education policy: Lessons and experiences from sub-Saharan Africa. Six case studies and 
reflections from the DAE Biennal Meetings, Tours, France.

SAIDE (2004). Criteria for quality distance education in South Africa: A policy statement. South Africa: SAIDE.

SARDEC (2005). Report of the SARDEC ODL situational assessment in Southern Africa. http://www.sardec.org.bw/reports.htm

Sauvé, L. (1993). What's behind the development of a course on the concept of distance education? In D. Keegan (Ed.), Theoretical principles of distance education. UK: Routledge.

Siaciwena, R., \& Lubinda, F. (2008). The role of open and distance learning in the implementation of the right to education in Zambia. The International Review of Research in Open and Distance Learning, 8(3). http://www.irrodl.org/index.php/irrodl/article/view/481/999

Sherry, A. C. (2003). Quality and its measurement in distance education implementation. In M.G. Moore \& W.G. Anderson (Eds.), Handbook of distance education (pp. 436460). New Jersey: Lawrence Erlbaum Associates, Inc.

Simonson, M., \& Bauck, T. (2003). Distance education policy issues: Statewide perspectives. In M. G. Moore \& W. G. Anderson (Eds.), Handbook of distance education (pp. 417-424). Mahwah, NJ: Lawrence Erlbaum.

TEC. (2001). Consultation paper on distance education in Mauritius. Réduit: Tertiary Education Commission.

Tresman, S. (2002). Towards a strategy for improved student retention in programmes of open, distance education: A case study from the open university, UK. International Review of Research in Open and Distance Learning, 3(1). Retrieved August 19, 2007, from http://www.irrodl.org/index.php/irrodl/article/view/75/145

Trochim, W. (2006). Research methods: The concise knowledge base. USA: Atomic Dog Publishing. http://www.socialresearchmethods.net/kb/sampnon.php

UNESCO Institute for Statistics (2007). Global education digest 2006: Comparing education statistics across the world. http://www/uis.unesco.org/ev.php?ID=6827 201\&ID2=DO TOPIC

Wallet, J., \& Guidon, J. (Eds.) (2007). Formation à distance en Afrique Sub-Saharienne francophone: Etudes comparées. Paris: UNESCO / BREDA/ADEA. http://www.edusud.org/adea/publi adea format web 5 decembre.pdf 
Watkins, R., \& Kaufman, R. (2003). Strategic planning for distance education. In M. G. Moore \& W. G. Anderson (Eds.), Handbook of distance education. (pp. 507-518). Mahwah, NJ: Lawrence Erlbaum.

World Bank. (2009). Data and statistics: Country classifications. http://web.worldbank.org/WBSITE/EXTERNAL/DATASTATISTICS/0, contentMDK:0 420458 meuPK:64133156 pagePK:64133150 piPK:64133175 theSitePK:239419,00.ht $\mathrm{ml}$

Woudstria, A., \& Adria, M. (2003). Issues in organizing for the new network and virtual forms of distance education. In M.G. Moore \& W.G. Anderson (Eds.), Handbook of distance education (pp. 531-548). New Jersey: Lawrence Erlbaum Associates, Inc.

Young, M. (1989). Report on open learning and its potential in Mauritius with special reference to upgrading primary school teachers and the Mauritius College of the Air. Mauritius: Ministry of Education, Arts and Culture.

Youngman, F. (2002, April). Policy development for lifelong learning in Botswana. Interagency Strategic Group Meeting on Lifelong Learning. Organized by UNESCO and UNESCO Basic Education Division, Hamburg. 


\section{Appendix}

\section{INTERVIEW SCHEDULE FOR STAKEHOLDERS}

\section{Gender}

Age

Position within the University

Relationship with distance students

Type of distance education experience:

1. How long have you been involved in distance education provision?

2. Could you provide a detailed description of your particular involvement?

3. From your experience of distance education students, what do you think encourages students to stay on a program or to drop out from it?

4. What, do you think can be described as support strategies to encourage learners stay on a course or drop out of it?

5. Do you believe the students you deal with have access to the facilities you describe?

6. By what mechanisms, if any, do you systematically collect data regarding whether these strategies are adequate?

7. Does this feedback indicate whether these facilities are sufficient and will promote their retention or be predictors of their attrition?

8. How would you describe the quality of the program on offer with regards to students support services?

9. Do you have any suggestions for its improvement?

10. What are the possibilities that your suggestions will be implements at the University of Mauritius?

\section{INTERVIEW SCHEDULE FOR STUDENTS}

\section{Gender}

Age

Course level - Masters

$$
\begin{aligned}
& \text { Bachelors } \\
& \text { Diploma } \\
& \text { Certificate }
\end{aligned}
$$

\section{Type of distance education:}

1. Can you describe your learning experiences as a student - from school onwards? Is there any particular instance that you think is memorable and why? Why did you choose a distance learning course as opposed to a face to face one?

2. What are the factors that you can say help you enjoy this course?

3. What are the factors that prevent you from enjoying this course?

4. Can you describe reasons that would encourage you to say on this program AND reasons that would encourage you to drop out? 
5. What, according to you is meant by student support services?

6. Do you have access to all of these/some of these or none these? Do you think that you have access to these facilities at the time you require them?

7. If you have access to this range of facilities, would you say they are adequate or not adequate?

8. If you believe that they are not adequate, can you describe what else would you need in terms of support to make you view your educational experience as a totally satisfying one?

9. If you do need some kind of support that you believe is necessary at that given point in time, would you ask for it? Would you have access to it?

10. From your experience as a student, would you say the same type of support facilities exist for both types of distance learning formats at the University?

11. Which type of distance education would you prefer if you had a choice - the classical or the online type?

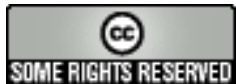

